\title{
Small-size Jatropha Seed Biochar Extracted from Microwave Pyrolysis: Optimization of Its Biocomposites Mechanical Properties by Mixture Design
}

\author{
Perry Law Nyuk Khui, ${ }^{a}$ Md. Rezaur Rahman, ${ }^{\text {a,* }}$ Kuok King Kuok, ${ }^{b}$ Muhammad \\ Khusairy Bin Bakri, ${ }^{a}$ Muhammad Adamu ${ }^{\mathrm{a}}$, Diana Tazeddinova, ${ }^{\mathrm{c}}$ Zhumayeva A. \\ Kazhmukanbetkyzy, ${ }^{\mathrm{d}}$ and Baibatyrov Torebek ${ }^{\mathrm{d}}$
}

\begin{abstract}
Microwave pyrolysis of finely ground jatropha seed biochar was used as bio-filler to develop biocomposites. Effects influencing the mechanical properties of the biocomposites were investigated based on varied material ratio. Ratios by percentage of weight were determined by $D$ optimal (custom) mixture design using the Stat Ease "Design Expert". The mechanical properties, such as tensile strength, modulus of elasticity, and microhardness, were the dependent variables (response). Bio-filler content was optimised to attain the overall best mechanical properties for the biocomposites. The optimized biocomposite that showcased good tensile strength, modulus of elasticity, and microhardness biocomposite ratio's predicted mechanical properties mean values were tensile strength (9.53 MPa), modulus of elasticity (0.730 GPa), and microhardness (20.4 $\mathrm{HV}$ ) for polylactic acid and biofiller mixture; and tensile strength (7.92 $\mathrm{MPa})$, modulus of elasticity $(0.668 \mathrm{GPa})$, and microhardness $(18.7 \mathrm{HV})$ for polylactic acid, biofiller, and poly(ethylene-alt-maleic anhydride) mixture. Models generated by the mixture design showcased some degree of noise and error present; however, the outcome through the optimization step was generally reliable for predicting the mechanical properties. Additional data gathered through experimental testing and replicates could improve the reliability of the model.
\end{abstract}

Keywords: Composite; Biochar; D-optimal mixture design; Mechanical properties

Contact information: a: Faculty of Engineering, Universiti Malaysia Sarawak, Jalan Datuk Mohammad Musa, Kota Samarahan, Sarawak 94300 Malaysia; b: Faculty of Engineering, Computing and Science, Swinburne University of Technology Sarawak Campus, Jalan Simpang Tiga, Kuching, Sarawak 93350 Malaysia; c: Faculty of Engineering, South Ural State University, 76, Lenin Prospekt, Chelyabinsk 454080 Russia; d: Zhangir Khan West Kazakhstan Agrarian - Technical University, Zhangir Khan St 51, Uralsk 090009 Kazakhstan; *Corresponding author: rmrezaur@unimas.my

\section{INTRODUCTION}

Microwave pyrolysis of jatropha seeds has been used in a few studies to produce biochar (Das et al. 2018; Law et al. 2021). The pyrolysis extraction tool produced good oil yields, particularly from jatropha seeds, suggesting that it could be used as a biodiesel fuel (Kanaujia et al. 2016; Sugumaran et al. 2017; Ruggiero et al. 2019). The excess or remaining material after pressing a larger quantity of oil from the fruits and nuts is sometimes poisonous and must be chemically treated before being used as agricultural feedstock or dumped in landfills (Ruggiero et al. 2019). The use of Jatropha curcas L. fruits and seeds as an alternate source of ecological biodiesel and possible filler in composites was motivated by advanced technologies (Law et al. 2021). Ball milling processes were used to successfully synthesise and characterise microwave pyrolysis 
jatropha seed biochar into very small size bio-filler (Law et al. 2020). As a result, the mechanical properties of biocomposites using the microwave pyrolysis jatropha seed biochar as bio-filler and biodegradable polymer matrix were optimised in this study.

The majority of biodegradable PLA biocomposites have shown high mechanical properties, such as cellulose microcrystalline fibres and nano-whiskers, carbon, wood fibres, and flour (Petersson et al. 2007; Belhamdi et al. 2016; Rahman et al. 2021). Wood, kenaf, bamboo, and hemp are the most common fibres or fillers used to incorporate in the PLA in biocomposites (Pan et al. 2007; Nyambo et al. 2010; Rahman et al. 2021). In comparison to neat PLA, most of the PLA biocomposites modulus was raised, and elongation at break was decreased (Chun et al. 2020). Carbon fibres or fillers, both natural and man-made, have been found to improve the mechanical properties of PLA-based composites ( $\mathrm{Li}$ et al. 2020). In terms of developing a composite with good tensile strength, numerous studies have employed laminates and continuous unidirectional oriented reinforcements to produce composites with higher tensile strength (McNally 2008; Yang et al. 2016; Hazer et al. 2018; Rajak et al. 2019). However, the bio-filler utilized is considered as micro-nano particles reinforcements; hence, the composite is a particle reinforced composite. An improved hardness, wear resistance, and fracture toughness are the probable outcome (Ghalia and Abdelrasoul 2018; Rajak et al. 2019).

To optimise the bio-filler ratio and material usage with respect to the biocomposite mechanical properties, a design of experiments program by StatEase called "Design Expert" was used. Design of experiments is a statistical technique to evaluate the effects of linear, non-linear, and independent variables (e.g., bio-filler, polymer matrix) on dependent variables (mechanical properties) (Keinänen et al. 2018; Venkatesan et al. 2019; Zaib et al. 2019). The D-optimal (custom) mixture design uses the number of input variables to be one. Therefore, the measured response in the mixture configuration is independent of the volume of the mixture and depends only on the iterations of the components in the mixture (Hare 1991). Optimal modelling algorithms test the unbiased method parameter predictions for the lowest number of experimental runs in a mixture configuration (Jeirani et al. 2012; Varanda et al. 2017).

The response-dependent variables are the tensile strength, elasticity modulus, and Vickers microhardness. The significance of using this program is to predict and determine the optimum ratios for fabrication in favour of the best mechanical properties possibly achievable. For a simple bio-filler-to-matrix composite mixture, a D-optimal (custom) mixture design option was utilised. The program can simulate data that shows the optimum ratio, dependant to which parameter is desired to be maximised or minimised. As presented by StatEase and other researchers, the D-optimal (custom) mixture design approach used for response analyses and optimisation will be according to the standard protocol, so results may be comparative to other studies (Zarrinbakhsh et al. 2019; Radfar et al. 2020; Visetvichaporn et al. 2020).

Arrigo et al. noted that biochar-reinforced polylactic acid (PLA) biocomposites can be tailored to meet commercial specifications by optimising the biochar filler content and the suitable processing method. The researcher's findings present biochar as a suitable replacement for conventional fillers (i.e., carbon black, talc, and $\mathrm{CaCO}_{3}$ ). Hence, expanding the applicability of biochar and its biocomposites to applications such as building, packaging, automotive, and electronics (Das et al. 2018; Arrigo et al. 2020). Moreover, the low cost of production of bio-filler, combined with the ability to extract it from various waste sources, reflects an added benefit to the circular economy solution (Arrigo et al. 2020). 


\section{EXPERIMENTAL}

\section{Materials}

Bio-filler reinforcements used for biocomposite fabrication were synthesized based on the previous work by Law et al. (2020). The $30 \mathrm{hrs}$ ball milling filler was used. Polylactic acid (PLA) and poly(ethylene-alt-maleic anhydride) were supplied by Universiti Malaysia Sarawak (UNIMAS) (Kota Samarahan, Sarawak, Malaysia). A hydraulic molding press (GT-7014-A50C; GOTECH, Taichung City, Taiwan) was used, which has the capability of a dual functioning hot and cold pressing operation for biocomposite fabrication. A universal testing machine (MSC-5/500; Shimadzu, Kyoto, Japan) was used to conduct the tensile test for numerous mechanical properties from the biocomposite samples. A Vickers micro hardness tester (HMW-G21; Shimadzu, Kyoto, Japan) was used to conduct the microhardness test for the biocomposite samples. Most of the experimental testing was conducted at the chemical engineering department of Universiti Malaysia Sarawak (UNIMAS) (Kota Samarahan, Sarawak, Malaysia).

\section{Methods}

"D-optimal (custom) mixture design" with Design Expert software

A biocomposite ingredient mixture ratio, response analysis, and optimization were designed with software by StatEase called Design Expert (version 11, Minneapolis, MN, USA). Within the "Standard Designs" for Design Expert, D-optimal (Custom) Design was selected under the category "Mixture". This lets the user produce an array of filler and matrix content ratios, prior to biocomposite fabrication. A standard number of replicates and runs was selected to the minimum standard under the software guidelines. The following abbreviations were used for the ingredients in the mixture design and testing:

- $\quad$ PLA = Polylactic Acid

- $\quad$ PLA/PEMA = Polylactic Acid + Poly(ethylene-alt-maleic anhydride)

- $\mathrm{PLA} / \mathrm{BC}=$ Polylactic acid + Bio-filler

- $\mathrm{PLA} / \mathrm{PEMA} / \mathrm{BC}=$ Polylactic Acid + Poly(ethylene-alt-maleic anhydride $)+$ Bio-filler

\section{Mechanical tensile strength test for biocomposites}

The tensile strength test was conducted with a maximum loading capacity of 300 $\mathrm{kN}$ and a crosshead speed of $0.7 \mathrm{~mm} / \mathrm{min}$. A total of 5 runs were conducted for each sample ratio variation to attain an average value, according to the ASTM D638-14 (2014) testing standard TYPE IV, with a crosshead speed $5 \mathrm{~mm} / \mathrm{min}$.

\section{Vickers microhardness test for biocomposites}

A Vickers indenter with squared-based pyramidal-shaped diamond indenter with face angles of $136^{\circ}$ was used during the test. The force was setted at HV $0.3(2.942 \mathrm{~N})$, and the indenter was held for $10 \mathrm{~s}$. A total of 5 runs were conducted at different locations on the biocomposite to attain an average (HV) value, as per ASTM E384-17 (2005). The following calculation represent the Vickers microhardness formula (HV) equivalent to the units $\left(\mathrm{N} / \mathrm{mm}^{2}\right)$ in Eq. 1,

$$
H V=0.189\left(\frac{P}{d^{2}}\right)
$$

where $P$ is expressed in Newton units $(\mathrm{N})$, and $d$ is the average length of the diagonal left by the indenter $(\mathrm{mm})$. 


\section{RESULTS AND DISCUSSION}

Through comparing the bio-filler performance, it was observed that the overall tensile strength (TS) of the biocomposites did not improve with the increase in bio-filler content (Table 1). The interfacial bonding between polymer matrix and reinforcement were poor with high bio-filler content, and it was recommended to undergo modification of biofiller, such as surface functionalization (physical or chemical) (Poulose et al. 2018). A study shows a similar effect with the introduction of biochars, which allows the composite to sustained similar tensile strength as the control, with additional properties such as improved electrical conductivity and thermal degradation (Nan et al. 2015).

Table 1. D-optimal (Custom) Mixture Design for PLA/BC Biocomposites with Experimental Results as Response

\begin{tabular}{|c|c|c|c|c|c|}
\hline \multirow[b]{2}{*}{ Run No. } & Component 1 & Component 2 & Response 1 & Response 2 & Response 3 \\
\hline & PLA (wt\%) & $\mathrm{BC}(\mathrm{wt} \%)$ & $\begin{array}{c}\text { Hardness } \\
(\mathrm{HV})\end{array}$ & MOE (GPa) & TS (MPa) \\
\hline 1 & 99.5 & 0.5 & 19.2105 & 0.7272 & 10.2117 \\
\hline 2 & 98.375 & 1.625 & 20.8597 & 0.6849 & 10.3641 \\
\hline 3 & 98.375 & 1.625 & 20.1948 & 0.7759 & 11.2008 \\
\hline 4 & 98.375 & 1.625 & 19.9186 & 0.7074 & 11.3883 \\
\hline 5 & 98.375 & 1.625 & 20.103 & 0.6965 & 12.0680 \\
\hline 6 & 98 & 2 & 20.5707 & 0.7586 & 7.9476 \\
\hline 7 & 98.375 & 1.625 & 20.9592 & 0.7256 & 11.2055 \\
\hline 8 & 99.5 & 0.5 & 19.3837 & 0.5996 & 6.8906 \\
\hline 9 & 99.5 & 0.5 & 19.1250 & 0.7231 & 9.6398 \\
\hline 10 & 98.75 & 1.25 & 18.7876 & 0.7158 & 7.4226 \\
\hline 11 & 98.75 & 1.25 & 19.4720 & 0.6664 & 9.1054 \\
\hline 12 & 98.75 & 1.25 & 19.2116 & 0.6694 & 6.5062 \\
\hline 13 & 98.75 & 1.25 & 19.0399 & 0.6597 & 6.4570 \\
\hline 14 & 98.75 & 1.25 & 19.1261 & 0.6467 & 12.5953 \\
\hline 15 & 98 & 2 & 20.1957 & 0.6689 & 10.3055 \\
\hline 16 & 98 & 2 & 19.9192 & 0.7263 & 6.6679 \\
\hline 17 & 98 & 2 & 20.2881 & 0.8084 & 9.0656 \\
\hline 18 & 99.5 & 0.5 & 19.0399 & 0.583131 & 8.87813 \\
\hline 19 & 99.5 & 0.5 & 19.4722 & 0.683049 & 7.15547 \\
\hline 20 & 98 & 2 & 20.0103 & 0.659424 & 10.7883 \\
\hline
\end{tabular}

The modulus of elasticity (MOE) for the PLA/BC biocomposite and their iterations showed slight improvements. The iterations for PLA/PEMA/BC had a similar MOE range as the iterations for PLA/BC. The increased MOE can be attributed to the brittle behaviour of the biocomposite and affected the hardness, as well. These results were comparable to numerous studies, where biocarbon was used for reinforced polymer composites, whereas the tensile strength seemed to be maintained within the performance of the control samples with improved MOE (Nan et al. 2015; Poulose et al. 2018).

The PLA/BC increased in hardness as the bio-filler content increased. The high value of hardness of all samples was at $1.625 \mathrm{wt} \%$ for PLA/BC with a value of $21.0 \mathrm{HV}$. A similar study reported the usage of multi-wall carbon nanotubes (CNT) $(0.2 \mathrm{wt} \%)$ in epoxy resin without surface modification and with an average microhardness $21.7 \mathrm{HV}$, whereas the control epoxy resin was $21.3 \mathrm{HV}$. In addition, the surface modification on the 
CNT fillers enabled the polymer composite to achieve a microhardness value of 28.0 and 29.6 HV (Franceschi et al. 2015).

The results of the mechanical test results and filter-to-matrix content for PLA/BC biocomposites are presented in Table 1 . In total, there were 20 runs with replicates for each iteration $(0.5,1.25,1.625$, and $2.0 \mathrm{wt} \%)$. The response are individual mechanical test results for each sample, rather than an average value. The replicates increased the number of data points for the model to plot and produced the predicted values. The average values for the control samples mechanical properties were as follows:

Table 2. Average Mechanical Values for Control Samples

\begin{tabular}{|c|c|c|c|}
\hline Material & $\begin{array}{c}\text { Tensile Strength } \\
(\mathrm{MPa})\end{array}$ & $\begin{array}{c}\text { Modulus of } \\
\text { Elasticity (GPa) }\end{array}$ & Vickers Microhardness (HV) \\
\hline PLA & 11.6 & 0.679 & 18.7 \\
\hline PLA/PEMA & 17.8 & 1.38 & 19.7 \\
\hline
\end{tabular}

Table 3 shows that analysis of variance (ANOVA) utilized a quadratic model, which was a best fit for all responses in the mixture design for PLA/BC. However, the coded equation with variables $\mathrm{A}$ and $\mathrm{B}$ were the coding factors by design expert mixture design. Table 4 shows the tabulated diagnostic results of the predicted values versus the actual experimental values. In each run, the actual versus predicted value of TS (MPa) were varied in comparison to the values for hardness (HV) and MOE (GPa). Hence, the diagnostic results did correlate with the ANOVA results where it showed the model had a significant percentage that the predicted value in relation to the actual value were occurring due to noise.

Table 3. Analysis of Variance for PLA/BC Biocomposites Experimental Results

\begin{tabular}{|c|c|c|c|c|c|c|c|}
\hline Response & $\begin{array}{c}\text { Model } \\
\text { F-value }\end{array}$ & $\begin{array}{c}\text { Model } \\
\text { p-value }\end{array}$ & $\begin{array}{c}\text { Lack of Fit } \\
\text { F-value }\end{array}$ & Adj. $\mathrm{R}^{2}$ & $\begin{array}{c}\text { Pred. } \\
\mathrm{R}^{2}\end{array}$ & $\begin{array}{c}\text { Adeq. } \\
\text { Precision }\end{array}$ & $\begin{array}{c}\text { Pred. } \\
\text { Equation }\end{array}$ \\
\hline $\begin{array}{c}\text { Hardness } \\
(\mathrm{HV})\end{array}$ & 8.930 & 0.0022 & 24.39 & 0.4550 & 0.3763 & 6.5713 & $\begin{array}{c}\mathrm{HV}=19.18 \mathrm{~A}+ \\
20.39 \mathrm{~B}-1.08 \mathrm{AB}\end{array}$ \\
\hline $\begin{array}{c}\mathrm{MOE} \\
(\mathrm{GPa})\end{array}$ & 2.490 & 0.1125 & 0.730 & 0.1357 & $\begin{array}{c}- \\
0.1346\end{array}$ & 3.4900 & $\begin{array}{c}\mathrm{MOE}=0.6614 \mathrm{~A}+ \\
0.729 \mathrm{~B}-0.0513 \mathrm{AB}\end{array}$ \\
\hline $\mathrm{TS}(\mathrm{MPa})$ & 0.7300 & 0.4976 & 6.76 & $\begin{array}{c}- \\
-\end{array}$ & $\begin{array}{c}- \\
0.2597\end{array}$ & 1.7302 & $\begin{array}{c}\mathrm{UTS}=8.362 \mathrm{~A}+ \\
9.531 \mathrm{~B}+2.494 \mathrm{AB}\end{array}$ \\
\hline
\end{tabular}

The ANOVA produced by the mixture design for the PLA/BC hardness (HV) response showed the model F-value of 8.930, which implied that the model was significant. There was a $0.22 \%$ chance that an F-value that large was possibly due to noise. Model pvalue $(0.0022)$ was less than 0.05 , indicating the model terms were significant. The Lack of Fit F-value of 24.39 implied that the Lack of Fit is a relevant factor. According to the Design Expert based on ANOVA results, there was a $0.01 \%$ chance that the Lack of Fit Fvalue could occur due to noise. The predicted $\mathrm{R}^{2}$ of 0.3763 was in reasonable agreement with the adjusted $\mathrm{R}^{2}$ of 0.4550 because the difference was less than 0.2 . Adequate precision measured the signal to noise ratio. According to Design Expert, a ratio greater than 4 was desirable. The ratio of 6.571 indicated an adequate signal. This model was used to navigate the design space. 
Table 4. Diagnostic Results for Predicted Versus Actual Values for PLA/BC Biocomposites Experimental Results

\begin{tabular}{|c|c|c|c|c|c|c|}
\hline \multirow{3}{*}{ Run No. } & \multicolumn{2}{|c|}{ Hardness (HV) } & \multicolumn{2}{c|}{ MOE (GPa) } & \multicolumn{2}{c|}{ TS (MPa) } \\
\cline { 2 - 7 } & $\begin{array}{c}\text { Actual } \\
\text { Value }\end{array}$ & $\begin{array}{c}\text { Predicted } \\
\text { Value }\end{array}$ & $\begin{array}{c}\text { Actual } \\
\text { Value }\end{array}$ & $\begin{array}{c}\text { Actual } \\
\text { Value }\end{array}$ & $\begin{array}{c}\text { Predicted } \\
\text { Value }\end{array}$ & $\begin{array}{c}\text { Actual } \\
\text { Value }\end{array}$ \\
\hline 1 & 19.21 & 19.18 & 0.7272 & 0.6614 & 10.21 & 8.36 \\
\hline 2 & 20.86 & 19.89 & 0.685 & 0.7032 & 10.36 & 9.71 \\
\hline 3 & 20.19 & 19.89 & 0.776 & 0.7032 & 11.2 & 9.71 \\
\hline 4 & 19.92 & 19.89 & 0.7074 & 0.7032 & 11.39 & 9.71 \\
\hline 5 & 20.1 & 19.89 & 0.6965 & 0.7032 & 12.07 & 9.71 \\
\hline 6 & 20.57 & 20.39 & 0.7587 & 0.7300 & 7.95 & 9.53 \\
\hline 7 & 20.96 & 19.89 & 0.7257 & 0.7032 & 11.21 & 9.71 \\
\hline 8 & 19.38 & 19.18 & 0.5996 & 0.6614 & 6.89 & 8.36 \\
\hline 9 & 19.13 & 19.18 & 0.7231 & 0.6614 & 9.64 & 8.36 \\
\hline 10 & 18.79 & 19.52 & 0.7158 & 0.6828 & 7.42 & 9.57 \\
\hline 11 & 19.47 & 19.52 & 0.6665 & 0.6828 & 9.11 & 9.57 \\
\hline 12 & 19.21 & 19.52 & 0.6695 & 0.6828 & 6.51 & 9.57 \\
\hline 13 & 19.04 & 19.52 & 0.6598 & 0.6828 & 6.46 & 9.57 \\
\hline 14 & 19.13 & 19.52 & 0.6467 & 0.6828 & 12.6 & 9.57 \\
\hline 15 & 20.2 & 20.39 & 0.669 & 0.73 & 10.31 & 9.53 \\
\hline 16 & 19.92 & 20.39 & 0.7264 & 0.73 & 6.67 & 9.53 \\
\hline 17 & 20.29 & 20.39 & 0.8084 & 0.73 & 9.07 & 9.53 \\
\hline 18 & 19.04 & 19.18 & 0.5831 & 0.6614 & 8.88 & 8.36 \\
\hline 19 & 19.47 & 19.18 & 0.683 & 0.6614 & 7.16 & 8.36 \\
\hline 20 & 20.01 & 20.39 & 0.6594 & 0.73 & 10.79 & 9.53 \\
\hline
\end{tabular}

The ANOVA produced by mixture design for the PLA/BC MOE (GPa) response showed that the model F-value of 2.49 implied the model was not significant relative to the noise. There was a $11.25 \%$ chance that an F-value that large could occur due to noise. The model p-value $(0.1125)$ was greater than 0.05 , hence model terms were not significant. The Lack of Fit F-value of 0.73 implied that the Lack of Fit was not significant relative to the pure error. There was a $40.55 \%$ chance that a Lack of Fit F-value that large could occur due to noise. A negative predicted $\mathrm{R}^{2}$ of -0.1346 implied that the overall mean was a better predictor of the response than the current model. An adequate precision ratio of 3.49 indicated an inadequate signal to use this model to navigate the design space.

The ANOVA for the PLA/BC TS (MPa) response showed that the model F-value of 0.73 implied that the model was not significant relative to the noise. There was a $49.76 \%$ chance that an F-value that large could occur due to noise. The model p-value (0.4976) was less than 0.05 , indicating that the model terms were significant to PLA/BC TS, which was directly taken from the Design Expert. The Lack of Fit F-value of 6.76 implied that the lack of fit was significant. There was only a $1.93 \%$ chance that a Lack of Fit F-value that large could occur due to noise. A negative predicted $R^{2}$ of -0.2597 implied that the overall mean was a better predictor of the response than the current model. Adequate precision measured the signal to noise ratio. A ratio of 1.73 indicated an inadequate signal and the model was inadequate to navigate the design space.

Similar studies utilizing D-optimal (custom) mixture design describe that the contribution of significant and not significant indications by the ANOVA influenced the model usability and reliability (Homkhiew et al. 2014; Radfar et al. 2020). Noise percentages generated by the mixture design were regarding the ANOVA values, because the least amount of noise percentage was desirable for the model. Similarly, the Lack of 
Fit of the model was desired to not be significant, as a fitting model with the least amount of noise was better at predicting the response, as well as minimising residuals between the predicted and response values (Homkhiew et al. 2014; Radfar et al. 2020).

The plotted graphs for the PLA/BC biocomposites predicted versus actual values generated by the mixture design are shown in Figs. 1 to 3. The HV plot for PLA/BC biocomposite shows a slightly better fitting model compared to the MOE and TS plots. Values that were closer to the linear plotted line resulted in a better model for optimisation, as the actual and predicted values had less residual value (Homkhiew et al. 2014).

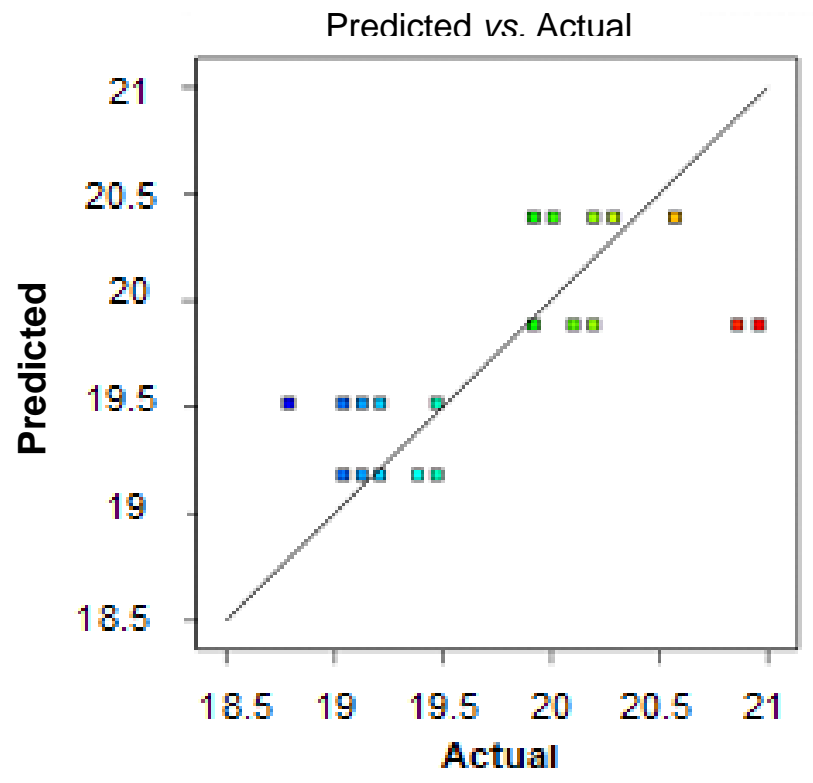

Fig. 1. Predicted versus actual hardness (HV) for PLA/BC biocomposites

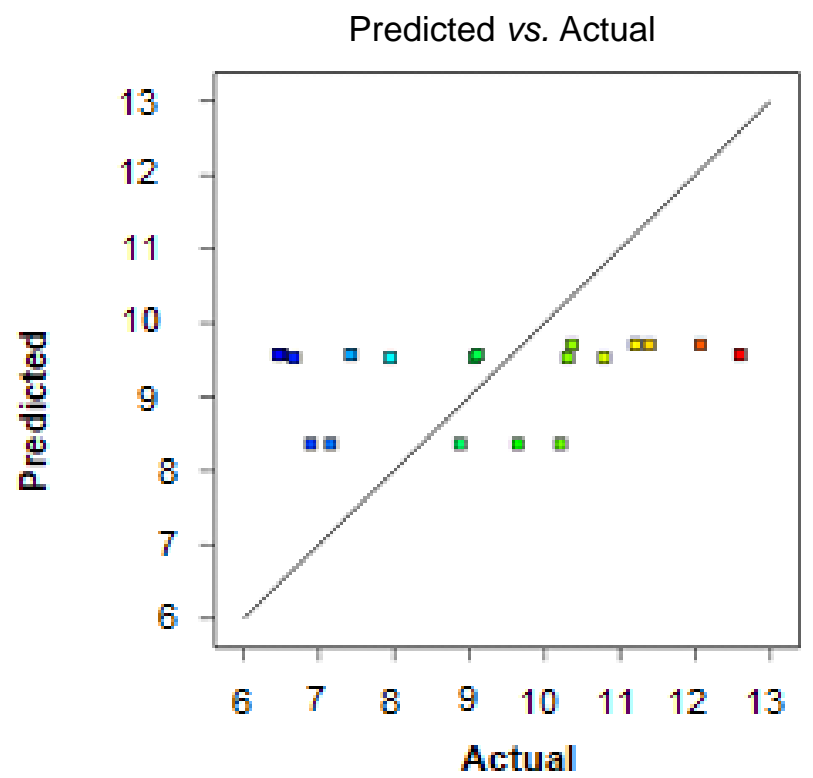

Fig. 2. Predicted versus actual tensile strength (TS) for PLA/BC biocomposites 


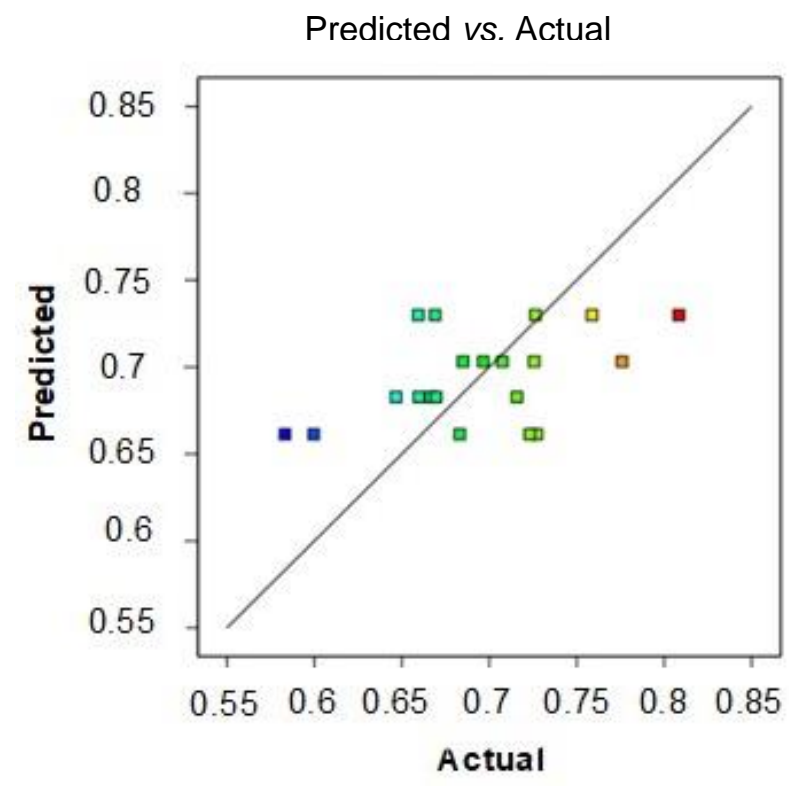

Fig. 3. Predicted versus actual modulus of elasticity (MOE) for PLA/BC biocomposites

The ANOVA for the PLA/PEMA/BC hardness (HV) response showed that the model F-value of 14.29 implied that the model was significant. There was a $0.02 \%$ chance that an F-value that large could occur due to noise. The model p-value (0.0002) was less than 0.05 and indicated that the model terms were significant. The Lack of Fit F-value of 2.49 implied that the lack of fit was not significant relative to the pure error. There was a $13.42 \%$ chance that a Lack of Fit F-value that large could occur due to noise. The predicted $\mathrm{R}^{2}$ of 0.4655 was in reasonable agreement with the adjusted $\mathrm{R}^{2}$ of 0.5831 , where the difference was less than 0.2. An adequate precision ratio of 8.522 indicated an adequate signal. This model was used to navigate the design space.

The ANOVA for the PLA/PEMA/BC MOE (GPa) response showed that the model F-value of 2.42 implied that the model was not significant relative to the noise. There was a $11.92 \%$ chance that an F-value that large could occur due to noise. The model p-value (0.1192) was greater than 0.05 and indicated that the model terms were not significant. Values greater than 0.1000 indicated that the model terms were not significant. The Lack of Fit F-value of 2.88 implied that the lack of fit was not significant relative to the pure error. There was a $10.89 \%$ chance that a Lack of Fit F-value that large could occur due to noise. A negative predicted $\mathrm{R}^{2}$ implied that the overall mean was a better predictor of the response than the current model. An adequate precision measured the signal to noise ratio. A ratio of 2.96 indicated an inadequate signal and should not use this model to navigate the design space.

The ANOVA for the PLA/PEMA/BC TS (MPa) response showed that the model F-value of 1.20 implied that the model was not significant relative to the noise. There was a $32.56 \%$ chance that an F-value that large could occur due to noise. Model p-value (0.3256) was more than 0.0500 indicated model terms were not significant. The Lack of Fit F-value of 0.27 implied that the lack of fit was not significant relative to the pure error. There was a $60.95 \%$ chance that a Lack of Fit F-value that large could occur due to noise. A negative predicted $\mathrm{R}^{2}$ implied that the overall mean was a better predictor of the response than the current model. In some cases, a higher order model was predicted better. Adequate precision measures the signal to noise ratio. A ratio of 2.20 indicated an inadequate signal and this model should not be used to navigate the design space. 
Table 5. D-Optimal (Custom) Mixture Design for PLA/PEMA/BC Biocomposites with Mechanical Results as Response

\begin{tabular}{|c|c|c|c|c|c|c|}
\hline \multirow{3}{*}{ Run No. } & $\begin{array}{c}\text { Component } \\
1\end{array}$ & $\begin{array}{c}\text { Component } \\
2\end{array}$ & $\begin{array}{c}\text { Component } \\
3\end{array}$ & $\begin{array}{c}\text { Response } \\
1\end{array}$ & $\begin{array}{c}\text { Response } \\
2\end{array}$ & $\begin{array}{c}\text { Response } \\
3\end{array}$ \\
\cline { 2 - 7 } & PLA (wt\%) & BC (wt\%) & $\begin{array}{c}\text { PEMA } \\
(\text { wt\%) }\end{array}$ & $\begin{array}{c}\text { Hardness } \\
(\mathrm{HV})\end{array}$ & $\begin{array}{c}\text { MOE } \\
(\mathrm{GPa})\end{array}$ & TS (MPa) \\
\hline 1 & 97 & 2 & 1 & 20.0092 & 0.6712 & 10.6617 \\
\hline 2 & 97.75 & 1.25 & 1 & 19.0399 & 0.6532 & 5.9460 \\
\hline 3 & 97.375 & 1.625 & 1 & 19.1237 & 0.7093 & 9.4640 \\
\hline 4 & 97.375 & 1.625 & 1 & 19.0396 & 0.6926 & 6.3703 \\
\hline 5 & 98.5 & 0.5 & 1 & 18.5405 & 0.6859 & 11.4281 \\
\hline 6 & 97.75 & 1.25 & 1 & 18.5399 & 0.6043 & 7.4718 \\
\hline 7 & 98.5 & 0.5 & 1 & 19.2965 & 0.7459 & 7.0195 \\
\hline 8 & 97.75 & 1.25 & 1 & 18.4587 & 0.6707 & 9.3632 \\
\hline 9 & 98.5 & 0.5 & 1 & 19.1250 & 0.6919 & 9.8906 \\
\hline 10 & 97 & 2 & 1 & 19.5614 & 0.7152 & 9.2343 \\
\hline 11 & 98.5 & 0.5 & 1 & 19.5609 & 0.7191 & 10.1344 \\
\hline 12 & 97.375 & 1.625 & 1 & 18.6218 & 0.6601 & 6.7054 \\
\hline 13 & 98.5 & 0.5 & 1 & 18.8699 & 0.6890 & 7.2445 \\
\hline 14 & 97.375 & 1.625 & 1 & 18.8699 & 0.7063 & 8.3414 \\
\hline 15 & 97 & 2 & 1 & 19.4708 & 0.7535 & 8.7726 \\
\hline 16 & 97.75 & 1.25 & 1 & 19.0407 & 0.6755 & 9.2132 \\
\hline 17 & 97.375 & 1.625 & 1 & 18.7878 & 0.6973 & 8.1445 \\
\hline 18 & 97 & 2 & 1 & 20.4758 & 0.6543 & 8.6812 \\
\hline 19 & 97.75 & 1.25 & 1 & 19.0388 & 0.6730 & 8.5875 \\
\hline 20 & 97 & 2 & 1 & 20.0095 & 0.6757 & 6.9445 \\
\hline
\end{tabular}

Table 6. ANOVA Results for PLA/PEMA/BC Biocomposites Mechanical Properties

\begin{tabular}{|c|c|c|c|c|c|c|c|}
\hline Response & $\begin{array}{c}\text { Model } \\
\text { F- } \\
\text { value }\end{array}$ & $\begin{array}{c}\text { Model } \\
\text { p-value }\end{array}$ & $\begin{array}{c}\text { Lack of } \\
\text { Fit F- } \\
\text { value }\end{array}$ & Adj. $R^{2}$ & $\begin{array}{c}\text { Pred. } \\
R^{2}\end{array}$ & $\begin{array}{c}\text { Adeq. } \\
\text { Precision }\end{array}$ & $\begin{array}{c}\text { Pred. } \\
\text { Equation }\end{array}$ \\
\hline $\begin{array}{c}\text { Hardness } \\
(\mathrm{HV})\end{array}$ & 14.29 & 0.0002 & 2.4900 & 0.5831 & 0.4654 & 8.5221 & $\begin{array}{c}\mathrm{HV}=19.101 \mathrm{~A}+ \\
19.8379 \mathrm{~B}-3.1225 \mathrm{AB}\end{array}$ \\
\hline $\begin{array}{c}\mathrm{MOE} \\
(\mathrm{GPa})\end{array}$ & 2.42 & 0.1192 & 2.8800 & 0.1298 & $\begin{array}{c}- \\
0.0976\end{array}$ & 2.9571 & $\begin{array}{c}\mathrm{MOE}=0.70425 \mathrm{~A}+ \\
0.7005 \mathrm{~B}-0.1362 \mathrm{AB}\end{array}$ \\
\hline $\mathrm{TS}(\mathrm{MPa})$ & 1.20 & 0.3256 & 0.2714 & 0.0205 & $\begin{array}{c}- \\
0.2522\end{array}$ & 2.2049 & $\begin{array}{c}\text { UTS }=9.1769 \mathrm{~A}+ \\
8.7582 \mathrm{~B}-4.2101 \mathrm{AB}\end{array}$ \\
\hline
\end{tabular}

Comparing the adequacy between the ANOVA of PLA/BC and PLA/PEMA/BC, the model and predicted values for PLA/PEMA/BC were slightly more reliable because of the noise level and significance of the ANOVA values. In terms of $\mathrm{R}^{2}$ values and adequate precision, the design expert guidelines, as supported by other studies, elaborated that an $\mathrm{R}^{2}$ closer to the value of 1.000 contributed to a model which was reliable and could predict the responses satisfactorily (Homkhiew et al. 2014; Radfar et al. 2020).

The plotted graphs of the PLA/PEMA/BC biocomposites predicted versus actual values generated by the mixture design were as shown in Figs. 4 to 6. In addition, the HV plot for the PLA/PEMA/BC biocomposite had a slightly better fitting model compared to the MOE and TS plots, similarly as the PLA/BC plots did. 
Generated optimum mixture content were as follows: PLA/BC mixture $=$ PLA $(98$ $\mathrm{wt} \%)$ and BC (2 wt $\%) ;$ PLA/PEMA/BC mixture = PLA (97.75 wt $\%)$, PEMA (1 wt $\%)$, and $\mathrm{BC}(1.25 \mathrm{wt} \%)$.

Table 7. Results for Actual versus Predicted Values for PLA/PEMA/BC Biocomposites Mechanical Properties

\begin{tabular}{|c|c|c|c|c|c|c|}
\hline \multirow{2}{*}{$\begin{array}{c}\text { Run } \\
\text { No. }\end{array}$} & \multicolumn{2}{|c|}{ Hardness (HV) } & \multicolumn{2}{c|}{ MOE (GPa) } & \multicolumn{2}{c|}{ TS (MPa) } \\
\cline { 2 - 7 } & $\begin{array}{c}\text { Actual } \\
\text { Value }\end{array}$ & $\begin{array}{c}\text { Predicted } \\
\text { Value }\end{array}$ & $\begin{array}{c}\text { Actual } \\
\text { Value }\end{array}$ & $\begin{array}{c}\text { Predicted } \\
\text { Value }\end{array}$ & $\begin{array}{c}\text { Actual } \\
\text { Value }\end{array}$ & $\begin{array}{c}\text { Predicted } \\
\text { Value }\end{array}$ \\
\hline 1 & 20.0092 & 19.83796 & 0.671274 & 0.700495 & 10.6617 & 8.758255 \\
\hline 2 & 19.0399 & 18.68884 & 0.653249 & 0.668319 & 5.94609 & 7.915108 \\
\hline 3 & 19.1237 & 19.06824 & 0.709326 & 0.675892 & 9.46406 & 8.073553 \\
\hline 4 & 19.0396 & 19.06824 & 0.692613 & 0.675892 & 6.37031 & 8.073553 \\
\hline 5 & 18.5405 & 19.10102 & 0.685914 & 0.704259 & 11.4281 & 9.176988 \\
\hline 6 & 18.5399 & 18.68884 & 0.604345 & 0.668319 & 7.47188 & 7.915108 \\
\hline 7 & 19.2965 & 19.10102 & 0.745993 & 0.704259 & 7.01953 & 9.176988 \\
\hline 8 & 18.4587 & 18.68884 & 0.670788 & 0.668319 & 9.36328 & 7.915108 \\
\hline 9 & 19.125 & 19.10102 & 0.69194 & 0.704259 & 9.89063 & 9.176988 \\
\hline 10 & 19.5614 & 19.83796 & 0.715214 & 0.700495 & 9.23438 & 8.758255 \\
\hline 11 & 19.5609 & 19.10102 & 0.719189 & 0.704259 & 10.1344 & 9.176988 \\
\hline 12 & 18.6218 & 19.06824 & 0.6601 & 0.675892 & 6.70547 & 8.073553 \\
\hline 13 & 18.8699 & 19.10102 & 0.68904 & 0.704259 & 7.24453 & 9.176988 \\
\hline 14 & 18.8699 & 19.06824 & 0.706338 & 0.675892 & 8.34141 & 8.073553 \\
\hline 15 & 19.4708 & 19.83796 & 0.75354 & 0.700495 & 8.77266 & 8.758255 \\
\hline 16 & 19.0407 & 18.68884 & 0.67553 & 0.668319 & 9.21328 & 7.915108 \\
\hline 17 & 18.7878 & 19.06824 & 0.697316 & 0.675892 & 8.14453 & 8.073553 \\
\hline 18 & 20.4758 & 19.83796 & 0.654378 & 0.700495 & 8.68125 & 8.758255 \\
\hline 19 & 19.0388 & 18.68884 & 0.673006 & 0.668319 & 8.5875 & 7.915108 \\
\hline 20 & 20.0095 & 19.83796 & 0.67573 & 0.700495 & 6.94453 & 8.758255 \\
\hline
\end{tabular}

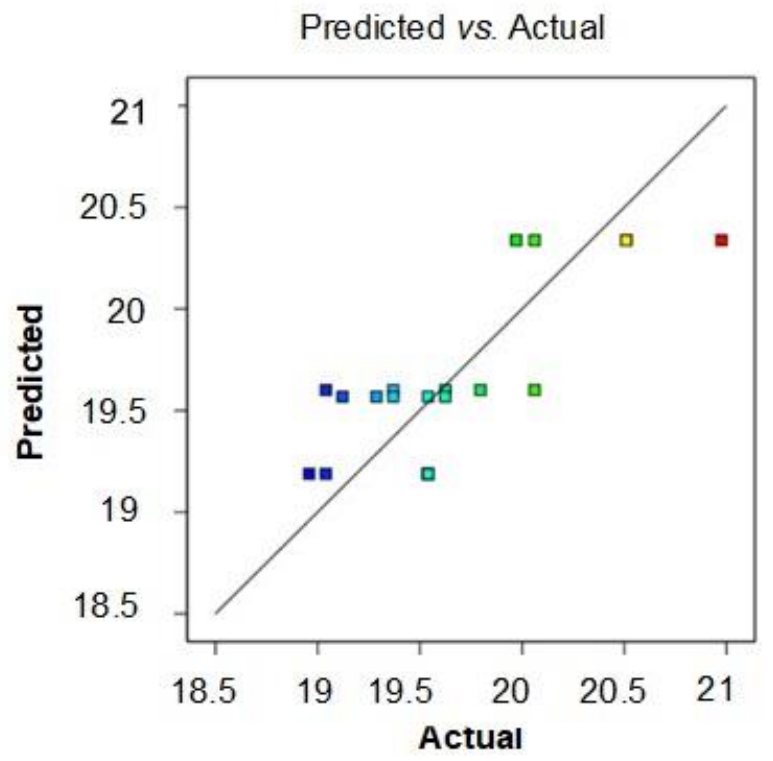

Fig. 4. Predicted versus actual hardness (HV) for PLA/PEMA/BC biocomposites 


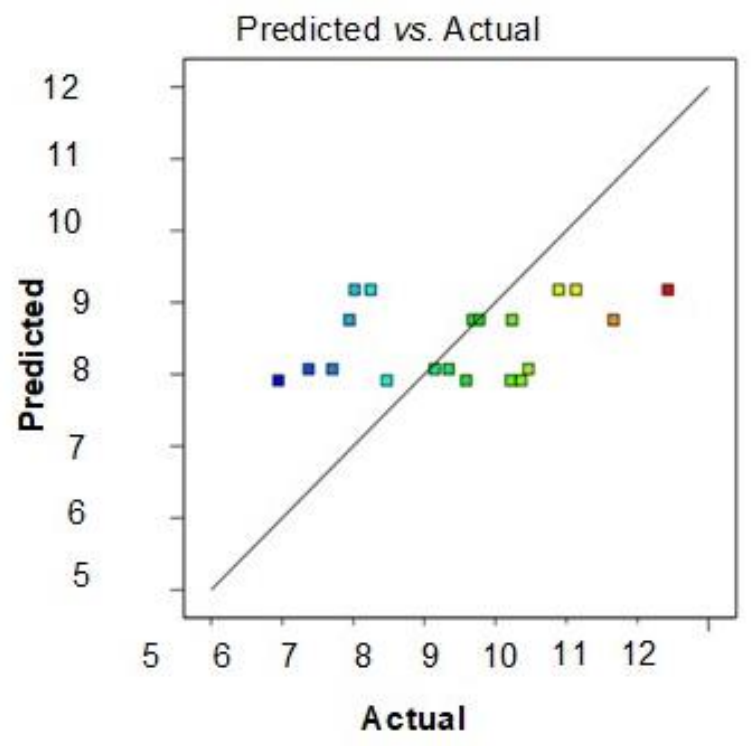

Fig. 5. Predicted versus actual tensile strength (TS) for PLA/PEMA/BC biocomposites

Predicted vs. Actual

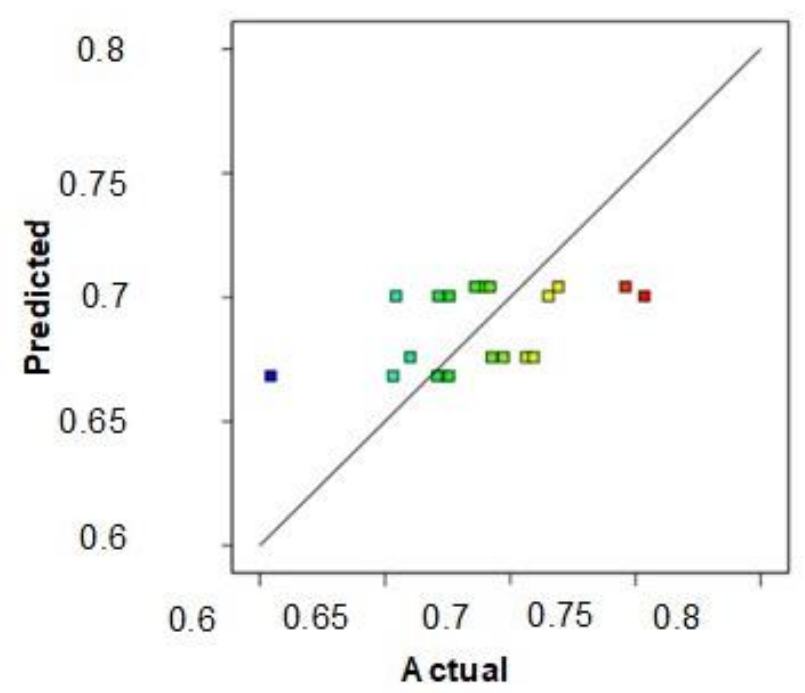

Fig. 6. Predicted versus actual modulus of elasticity (GPa) for PLA/PEMA/BC biocomposites

Table 8. Optimum Mixture Predicted Values for Maximizing Overall Mechanical Properties

\begin{tabular}{|c|c|c|c|c|c|c|c|c|c|}
\hline \multirow{4}{*}{$\begin{array}{l}\text { PLA } \\
\text { /BC }\end{array}$} & Resp. & $\begin{array}{l}\text { Pred. } \\
\text { Mean }\end{array}$ & $\begin{array}{c}95 \% \\
\text { PI Low }\end{array}$ & $\begin{array}{c}95 \% \text { PI } \\
\text { High }\end{array}$ & \multirow{4}{*}{$\begin{array}{l}\mathrm{PLA} / \mathrm{PE} \\
\mathrm{MA} / \mathrm{BC}\end{array}$} & Resp. & $\begin{array}{l}\text { Pred. } \\
\text { Mean }\end{array}$ & $\begin{array}{l}95 \% \mathrm{PI} \\
\text { Low }\end{array}$ & $\begin{array}{c}95 \% \text { PI } \\
\text { High }\end{array}$ \\
\hline & $\begin{array}{c}\text { Hardness } \\
(\mathrm{HV})\end{array}$ & 20.391 & 19.300 & 21.483 & & $\begin{array}{c}\text { Hardness } \\
\text { (HV) }\end{array}$ & 18.688 & 17.906 & 19.471 \\
\hline & $\begin{array}{l}\mathrm{MOE} \\
(\mathrm{GPa})\end{array}$ & 0.729 & 0.613 & 0.846 & & $\begin{array}{l}\text { MOE } \\
\text { (GPa) }\end{array}$ & 0.668 & 0.597 & 0.738 \\
\hline & TS (MPa) & 9.531 & 4.926 & 14.136 & & TS (MPa) & 7.915 & 4.594 & 11.235 \\
\hline
\end{tabular}


According to the mixture design generated, the composite mixture suggested the requirement of retesting of similar mixture content to obtain more data for optimisation. The model predicted that both PLA/BC and PLA/PEMA/BC at the suggested mixture contents were in the optimum zone for the composite material for best overall mechanical properties for a harder and stronger performing composite material. Other studies have shown confirmation of the optimised mixture and compared the predicted and observed values of the response (Homkhiew et al. 2014; Radfar et al. 2020).

\section{CONCLUSIONS}

1. The mixture design generated a reliable model of predicted values of the mechanical properties of the biocomposites. The mixture design presented the ability to optimise the overall mechanical properties of the biocomposites, maximising and minimising the materials used for fabrication. This is useful for future production of the biocomposites, catering to commercial usage.

2. Biocomposites developed were comparable to other studies, which are applicable for different applications (e.g., building, packaging, automotive, and electronics).

3. The variance in noise and error in the mixture design were according to the varied changes of the mechanical test results (experimental results). As more experimental data was collected, the mixture design increased in reliability to predict the optimum ratio in respect to tensile strength, modulus of elasticity, and microhardness responses.

\section{ACKNOWLEDGEMENTS}

The authors wish to acknowledge the Faculty of Engineering, Universiti Malaysia Sarawak (UNIMAS) for their lab facilities support.

\section{REFERENCES CITED}

Arrigo, R., Bartoli, M., and Malucelli, G. (2020). "Poly(lactic acid)-Biochar biocomposites: Effect of processing and filler content on rheological, thermal, and mechanical properties," Polymers-Basel 12(4), Article Number 892. DOI: 10.3390/polym12040892

ASTM D638-14 (2014). "Standard test method for tensile properties of plastics," ASTM International, West Conshohocken, PA, USA.

ASTM E384-05a (2005). "Standard test method for microindentation hardness of materials," ASTM International, West Conshohocken, PA, USA.

Belhamdi, B., Merzougui, Z., Trari, M., and Addoun, A. (2016). “A kinetic, equilibrium and thermodynamic study of 1-phenylalanine adsorption using activated carbon based on agricultural waste (date stones)," J. Appl. Res. Technol. 14(5), 354-366. DOI: 10.1016/j.jart.2016.08.004

Chun, K. S., Yeng, C. M., May, C. P., Yeow, T. K., Kiat, O. T., and How, C. K. (2020). "Effect of coupling agent content on properties of composites made from polylactic 
acid and chrysanthemum waste," J. Vinyl Addit. Technol. 26(1), 10-16. DOI: 10.1002/vnl.21710

Franceschi, W., Ferreira, F., V., Ferreira, E., V., Cividanes, L. D. S., Coutinho, A. D. R., Thim, G. P. (2015). "Functionalization of multi-walled carbon nanotube and mechanical property of epoxy-based nanocomposite," J. Aerosp. Technol. Manag. 7(3), 289-293. DOI: 10.5028/jatm.v7i3.485

Ghalia, M. A., and Abdelrasoul, A. (2018). "Compressive and fracture toughness of natural and synthetic fiber-reinforced polymer," in: Mechanical and Physical Testing of Biocomposites, Fibre-Reinforced Composites and Hybrid Composites, M. Jawaid, M. Thariq, and N. Saba (eds.),Woodhead Publishing Series in Composites Science and Engineering, Cambridge, UK, pp. 123-140.

Hare, L. (1991). "Experiments with mixtures: Designs, models and the analysis of mixture data," J. Qual. Technol. 23(2), 168-169. DOI:

10.1080/00224065.1991.11979309

Hazer, S., Coban, M., and Aytac, A. (2018). "A study on carbon fiber reinforced poly(lactic acid)/polycarbonate composites," J. Appl. Polym. Sci. 135(48), Article ID 46881. DOI: 10.1002/app.46881

Ho, L., Lambling, P., Bustamante, H., Duker, P., and Newcombe, G. (2011).

"Application of powdered activated carbon for the adsorption of cylindrospermopsin and microcystin toxins from drinking water supplies," Water Res. 45(9), 2954-2964. DOI: 10.1016/j.watres.2011.03.014

Homkhiew, C., Ratanawilai, T., and Thongruang, W. (2014). "The optimal formulation of recycled polypropylene/rubberwood flour composites from experiments with mixture design," Compos. Part B- Eng. 56, 350-357. DOI:

10.1016/j.compositesb.2013.08.041

Jeirani, Z., Mohamed Jan, B., Si Ali, B., Mohd. Noor, I., Chun Hwa, S., and Saphanuchart, W. (2012). "The optimal mixture design of experiments: Alternative method in optimizing the aqueous phase composition of a microemulsion," Chemometr. Intell. Lab. Syst. 112, 1-7. DOI: 10.1016/j.chemolab.2011.10.008

Kanaujia, P., Naik, D., Tripathi, D., Singh, R., Poddar, M. K., Konathala, L. N. S. K., and Sharma, Y. K., (2016). "Pyrolysis of Jatropha curcas seed cake followed by optimization of liquid-liquid extraction procedure for the obtained bio-oil," J. Anal. Appl. Pyrolysis. 118, 202-224. DOI: 10.1016/j.jaap.2016.02.005

Keinänen, P., Siljander, S., Koivula, M., Sethi, J., Sarlin, E., Vuorinen, J., and Kanerva, M. (2018). "Optimized dispersion quality of aqueous carbon nanotube colloids as a function of sonochemical yield and surfactant/CNT ratio," Heliyon 4(9), e00787. DOI: 10.1016/j.heliyon.2018.e00787

Law, P. N. K., Rahman, M. R., Hamdan, S., Jayamani, E., Bakri, M. K. B., and Sanaullah, K. (2020). "Synthesis and characterization of micro-nano carbon filler from jatropha seeds," BioResources 15(2), 3237-3251. DOI: 10.15376/biores.15.2.3237-3251

Law, P. N. K., Rahman, M. R., Ahmed, A. A., Kuok, K. K., Bakri, M. K. B., Tazeddinova, D., Kazhmukanbetkyzy, Z. A. and Torebek, B. (2021). "Morphological and thermal properties of composites prepared with poly(lactic acid), poly(ethylenealt-maleic anhydride), and biochar from microwave-pyrolyzed jatropha seeds," BioResources 16(2), 3171-3185. DOI: 10.15376/biores.16.2.3171-3185

Li, M., Pu, Y., Thomas, V. M., Yoo, C. G., Ozcan, S., Deng, Y., Nelson, K., and Ragauskas, A. J. (2020). "Recent advancements of plant-based natural fiber- 
reinforced composites and their applications," Compos. Part B: Eng. 200, 1-20. DOI: 10.1016/j.compositesb.2020.108254

McNally, D. (2008). "Short fiber orientation and its effects on the properties of thermoplastic composite materials," Polym. - Plas. Technol. Eng. 8(2), 101-154. DOI: $10.1080 / 03602557708545033$

Nan, N., Devallance, D., Xie, X., and Wang, J. (2015). "The effect of bio-carbon addition on the electrical, mechanical, and thermal properties of polyvinyl alcohol/biochar composites," J. Compos. Mater. 50(2), 1161-1168. DOI: 10.1177/0021998315589770

Nyambo, C., Mohanty, A. K., and Misra, M. (2010). "Polylactide-based renewable green composites from agricultural residues and their hybrids," BioMacromolecules 11(6), 1654-1660. DOI: 10.1021/bm1003114

Pan, P., Zhu, B., Kai, W., Serizawa, S., Iji, M., and Inoue, Y. (2007). “Crystallization behavior and mechanical properties of bio-based green composites based on poly(Llactide) and kenaf fiber," Journal of Applied Polymer Science 105(3), 1511-1520. DOI: 10.1002/app.26407

Petersson, L., Kvien, I., and Oksman, K. (2007). "Structure and thermal properties of poly(lactic acid)/cellulose whiskers nanocomposite materials," Composites Science and Technology 67(11-12), 2545-2544. DOI: 10.1016/j.compscitech.2006.12.012

Poulose, A. M., Elnour, A. Y., Anis, A., Shaikh, H., Al-Zahrani, S. M., George, J., AlWabel, M. I., Usman, A. R., Ok, Y. S., Tsang, D. C. W., et al. (2018). "Date palm biochar-polymer composites: An investigation of electrical, mechanical, thermal and rheological characteristics," Sci. Total Environ. 619-620, 311-318. DOI: 10.1016/j.scitotenv.2017.11.076

Radfar, R., Hosseini, H., Farhoodi, M., Ghasemi, I., Srednicka-Tober, D., and Shamloo, E. (2020). "Optimization of antibacterial and mechanical properties of an active LDPE/starch/nanoclay nanocomposite film incorporated with date palm seed extract using D-optimal mixture design approach," Int. J. Biol. Macromol. 158(1), 790-799. DOI: 10.1016/j.ijbiomac.2020.04.139

Rajak, D., Pagar, D., Menezes, P., and Linul, E. (2019). "Fiber-reinforced polymer composites: Manufacturing, properties, and applications," Polymers (Basel) 11(10), Article Number 1667. DOI: 10.3390/polym11101667

Rahman, M. R., Hamdan, S., and Bakri, M. K. B. (2021). "Polylactic acid activated bamboo carbon nanocomposites," in: Bamboo Polymer Nanocomposites. Rahman, M. R. (ed). Engineering Materials. Springer, Cham, pp. 63-82. DOI: 10.1007/978-3-03068090-9_4

Ruggiero, A., Valášek, P., Müller, M., and D’Amato, R. (2019). “Tribological investigation of epoxy/seed particle composite obtained from residues of processing Jatropha curcas L. fruits," Composites Part B: Engineering 167, 654-667. DOI: 10.1016/j.compositesb.2019.03.041

Sugumaran, V., Prakash, S., Ramu, E., Arora, A. K., Bansal, V., Kagdiyal, V., and Saxena, D. (2017). "Detailed characterization of bio-oil from pyrolysis of non-edible seed-cakes by Fourier transform infrared spectroscopy (FTIR) and gas chromatography mass spectrometry (GC-MS) techniques," J. Chromatogr. B. 1058, 47-56. DOI: 10.1016/j.jchromb.2017.05.014

Varanda, C., Portugal, I., Ribeiro, J., Silva, A. M. S., and Silva, C. M. (2017). "Optimization of bitumen formulations using mixture design of experiments (MDOE)," Constr. Build Mater. 156, 611-620. DOI:

10.1016/j.conbuildmat.2017.08.146 
Venkatesan, M., Zaib, Q., Shah, I. H., Park, H. S. (2019). "Optimum utilization of waste foundry sand and fly ash for geopolymer concrete synthesis using D-optimal mixture design of experiments," Resour. Conserv. Recycl. 148, 114-123. DOI: 10.1016/j.resconrec.2019.05.008

Visetvichaporn, V., Kim, K. H., Jung, K., Cho, Y. S., and Kim, D. D. (2020). "Formulation of self-microemulsifying drug delivery system (SMEDDS) by Doptimal mixture design to enhance the oral bioavailability of a new cathepsin $\mathrm{K}$ inhibitor (HL235)," Int. J. Pharm. 573, Article ID 118772. DOI: 10.1016/j.ijpharm.2019.118772

Wu, Q., Xian, Y., He, Z., Zhang, Q., Wu, J., Yang, G., Zhang, X., Qi, H., Ma, J., Xiao, Y., et al. (2019). "Adsorption characteristics of $\mathrm{Pb}$ (II) using biochar derived from spent mushroom substrate," Sci. Rep. 9(1), Article ID 15999. DOI: 10.1038/s41598019-52554-2

Yang, K., Ritchie, R., Gu, Y., Wu, S. J., and Guan, J. (2016). "High volume-fraction silk fabric reinforcements can improve the key mechanical properties of epoxy resin composites," Mater. Des. 108, 470-478. DOI: 10.1016/j.matdes.2016.06.128

Zaib, Q., Jouiad, M., and Ahmad, F. (2019). "Ultrasonic synthesis of carbon nanotubetitanium dioxide composites: Process optimization via response surface methodology," ACS Omega 4, 535-545. DOI: 10.1021/acsomega.8b02706

Zarrinbakhsh, N., Mohanty, A. K., and Misra, M. (2019). "Formulation optimization of bioreinforced composites from polyolefins and dried distiller's grains using statistical methods," Compos. Part A- Appl. S. 119, 246-260. DOI:

10.1016/j.compositesa.2019.01.017

Article submitted: January 3, 2021; Peer review completed: April 24, 2021; Revised version received: May 1, 2021; Revisions accepted: May 2, 2021; Published: May 5, 2021.

DOI: $10.15376 /$ biores. 16.3.4716-4730 